\title{
A estruturação da experiência segundo Luigi Giussani
}

\author{
The structuring of experience according \\ to Luigi Giussani
}

Miguel MAHFOUD

\section{Resumo}

O presente artigo apresenta a noção de experiência em sua dinâmica própria de estruturação segundo o pensamento de Luigi Giussani, apontando sua originalidade. Experiência tomada como inteligência do sentido das coisas que viabiliza o emergir do real à consciência e que é examinada em sua característica de incrementar a capacidade da pessoa de compreender e amar, bem como de abrir-se à totalidade. A originalidade da noção giussaniana de experiência é identificada na ênfase no acontecimento ao invés da característica moderna e contemporânea do sujeito subjugar o real, podendo superar as reduções da experiência a sentimento, a fenômeno subjetivo ou efêmero.

Palavras-chave: Experiência; Experiência elementar; Fenomenologia; Luigi Giussani; Psicologia humanista.

\begin{abstract}
This article presents the notion of experience in its own dynamic structure according to Luigi Giussani, pointing out its originality. Experience as intelligence of the meaning of things that enables the emergence from reality to consciousness is analyzed in view of its characteristic of increasing a person's ability to understand and love as well as to be open to totality. The originality of Giussani's notion of experience is the emphasis on the event rather than on the modern and contemporary characteristic of the subject suppressing reality, who might overcome the reductions of experience to a feeling, or a subjective or ephemeral phenomenon.
\end{abstract}

Keywords: Experience; Elemental experience; Phenomenology; Luigi Giussani; Humanistic psychology.

O presente artigo busca apresentar a noção de experiência em sua dinâmica própria de estruturação segundo o pensamento de Luigi Giussani, apontando sua originalidade. Luigi Giussani (1922-2005), educador, filósofo e teólogo italiano, tem sido objeto de atenção em diversas partes do mundo por sua contribuição original (Borghesi, 2015; Buzzi, 2003; Chiosso, 2009; Scola, 2006). Várias áreas do saber têm debatido, em seus campos específicos, problemas da cultura e da sociedade contemporâneas, a partir de suas contribuições. Particularmente sobre o conceito de

1 Universidade Federal de Minas Gerais, Faculdade de Filosofia e Ciências Humanas, Departamento de Psicologia. Av. Antônio Carlos, 6627, Caixa Postal 253, 31270-901, Belo Horizonte, MG, Brasil. E-mail: <mmahfoud@yahoo.com>. 
experiência elementar, destaca-se o trabalho do astrofísico Bersanelli (2013; Bersanelli \& Gargantini, 2003) no debate sobre metodologia científica; o de Chiosso (2004) no campo da educação; de Simoncini, Violini, Carozza, \& Cartabia (2011) no campo jurídico; e os de Konrad (2010) e Di Martino (2010) na Filosofia quanto a ética e teoria do conhecimento, respectivamente.

No Brasil, há alguns anos o conceito de experiência elementar vem sendo tomado em suas implicações para a Psicologia (Mahfoud, 2011, 2012). Quanto à sua noção de experiência, o próprio Giussani (1985, p.134) reconhece como "totalmente autóctone", afirmando sua originalidade.

Embora fundamental para a Psicologia, o tema experiência tem sido pouco enfrentado e se reconhece a necessidade de teorizações que deem conta da complexidade do fenômeno (Loureiro, 2015). Nesse sentido, o campo psi tem retomado a significativa contribuição de Bondía (2002), do campo da Educação, e de Ales Bello $(2006,2015)$ e Greuel (1998), ambos da Filosofia (Fenomenologia). O tema experiência, em seu desenvolvimento histórico-cultural e em sua radicalidade para a fundamentação de uma Psicologia da pessoa, pode ser consultado em Gaspar e Mahfoud (2006), Mahfoud e Massimi (2008) e Massimi e Mahfoud (2007).

\section{O ponto de partida}

Para se ter condições de examinar o que acontece aos seres humanos e à sua volta, Giussani (1977/2004, p.87) aponta a necessidade de se retomar a "situação original" de abertura, quando a consciência de si e do mundo estão indissociadas. Para exemplificar, o autor apresenta a afirmação "Antes eu não existia; agora eu existo" como uma evidência que promove um impacto capaz de despertar a consciência em termos da "situação original" (Giussani, 1977/2004, 1986/2009). Nessa posição, tem-se condições de superar as acepções empirista e racionalista de experiência - hegemônicas na cultura ocidental contemporânea -, podendo, então, ser apreendida na provocação do ser (Mahfoud \& Massimi, 2008; Massimi \& Mahfoud,
2007). Observar a própria experiência a partir de provocação tão específica - com a surpresa para com o próprio ser que a caracteriza -, abre caminho para que a pessoa chegue a dizer "eu" de um modo todo próprio, com respeito, cuidado e atenção para com o acontecimento mesmo da própria existência (Martins, 2007; Romano, 2008).

Assim, para Giussani, o ponto de partida para a problematização do que vem a ser experiência e sua estruturação própria não é uma definição teórica ou operacional, mas a surpresa diante da existência - existência essa que antecede, excede e supera qualquer decisão da própria pessoa. 0 acontecimento mesmo da existência pessoal convoca cada pessoa a estar presente no mundo da vida. $\mathrm{Na}$ "situação original", a pessoa tem condições de ser provocada pela existência de modo complexo, mais do que ela mesma formularia. Assim, a "situação original" de abertura atenta é a "estrutura originária" propriamente humana e pessoal (Severino, 2007) e o processo de desenvolvimento da experiência ruma de abertura em abertura até a experiência ontológica totalizante (Giannini, 1987).

A "situação original" pode ser reconhecida e redimensionada a cada fase do ciclo de vida de uma pessoa. Permanece válida e com força existencial contínua, retomando consciência viva e sempre resignificando constatações como "Eu poderia não estar aqui e estou" ou "Eu não poderia fazer a mim mesmo, mas eu sou".

A abertura ao ser como ponto de partida da elaboração propriamente pessoal indica que o fundamento da experiência não está no nível empírico: a experiência se estrutura a partir do juízo pessoal o qual se formula no acontecimento mesmo ao vivenciar qualquer coisa (Giussani, 1986/2009). "A experiência coincide, certamente, com 'provar' alguma coisa, mas coincide, sobretudo, com o juízo dado a respeito daquilo que se prova... . Um juízo exige um critério a partir do qual seja efetuado" (Giussani, 1986/2009, p.23). Um critério externo para formular experiências levaria o sujeito inevitavelmente à alienação, enquanto que só um critério originariamente pessoal permitiria juízos e, então, experiências próprias. "Todas as experiências da minha humanidade e da minha personalidade 
passam pelo crivo de uma 'experiência original', primordial, que constitui o meu rosto ao confrontar-me com tudo..., a experiência elementar" (Giussani, 1986/2009, p.24).

Cada vivência pode suscitar questões radicalmente importantes em termos existenciais, bem como fazer emergir exigências irrenunciáveis para a realização pessoal. Com o eu assim desperto e presente, faz-se experiência de cada coisa, de si mesmo e da totalidade contemporaneamente. Pode-se fazer experiência ao se ter o próprio eu despertado pelo real tirando o indivíduo da distração básica que caracteriza o envolvimento com o mundo da vida fixado nos interesses de cada um.

Para chegar a fazer experiência é fundamental a dimensão relacional. Assim, mesmo os desejos mais pessoais chegam a se formular e são reconhecidos nas vivências do mundo da vida - particularmente no acontecimento do real -, e na percepção viva de que o real é mais complexo do que a sensação imediata, é uma presença ainda que não claramente conhecida (entendida como percepção do mistério).

\section{Experiência e crescimento pessoal}

Pela dimensão relacional da existência pessoal, Giussani chega a afirmar que "concretamente, experiência é viver aquilo que me faz crescer" na capacidade de entender e de amar (Giussani, 1977/ 2004, p.87). Isto é, viver aquilo que nos faz crescer na capacidade de "descobrir seu sentido... na sua ligação com o resto" (Giussani, 1977/2004, p.88) - entendimento; e o que faz incrementar a capacidade de mergulhar "no ritmo do real e tender irresistivelmente para a unificação... até o significado exaustivo de uma coisa" (Giussani, 1977/2004, p.88) -, amor.

Com a mesma surpresa, a pessoa se dá conta de existir e de crescer. Na dimensão relacional, viver o que faz crescer e dar-se conta de crescer - viver o que faz a pessoa ser mais si mesma, dando-se conta da possibilidade de ser mais si mesma -, é capacidade de entender e de amar.

\section{Experiência e capacidade de entender}

Primeiramente, serão colocadas as características desse "crescer" como capacidade de entender. Como já foi exposto, para Giussani, experiência não é provar. Além disso, ele insiste no fato de que também não é fazer a si mesmo (Giussani, 1977/2004). Critica a expressão "fazer experiência" com a possível conotação de que "é o próprio sujeito que a faz". A pessoa elabora a experiência, mas não tem os termos à mão. Ou seja, faz-se experiência quando se tem a "inteligência do sentido das coisas" (Giussani, 1977/2004, 1986/2009). Assim, "inteligência" se refere a intus legere, à capacidade de ler o processo por dentro, de colher os elementos fundamentais do acontecimento e suas conexões com tudo mais (com o todo). Na expressão "inteligência do sentido das coisas", Giussani acentua que o sentido é reconhecido na conexão dos elementos no acontecimento do mundo da vida, na conexão da totalidade de seus elementos.

Assim, "experiência implica um critério de racionalidade, um critério avaliativo. Uma experiência que não seja racional não é uma experiência humana" (Giussani, 1988, p.215). "Não há outro caminho, no fundo, além dessa curiosidade desejosa despertada pelo pressentimento do verdadeiro" (Giussani, 1996, p.151): pessoa alguma poderia experienciar ou conhecer algo que não the despertasse uma curiosidade e um desejo, ou sem algum juízo pressentido no acontecimento. Dá-se experiência ao descobrir a conexão entre um elemento e outro, colhendo uma provocação pessoal, e provocando um crescimento de consciência de si ao responder a essa provocação.

\section{A realidade emerge à consciência segundo a totalidade dos fatores que a compõe. Mas o que quer dizer que emerge à consciência? Quer dizer que emerge a uma autocons- ciência: é objeto de sua autoconsciência, é como uma parte de si da qual você toma consciência. Mas isto o que é? Chama-se experiência (Giussani, 2000, p.50).}

Na relação afetiva fica evidente essa dinâmica: a experiência mais pessoalmente realizadora se dá justamente no momento em que se está voltado para o outro. Ali faz-se experiência do outro e de si mesmo a um só tempo e, assim, ganha-se 
autoconsciência nova ou, ainda, um olhar dirigido ao sujeito de modo pessoal descortina o conhecimento do outro e de si mesmo num único acontecimento cheio de juízo sobre si e sobre o mundo.

\section{Experiência e capacidade de amar}

Será examinada agora a concepção Giussaniana de experiência como viver aquilo que incrementa a capacidade de amar. Ao apreender um sentido, perceber uma conexão entre os elementos (não uma conexão inventada, mas a que se capta), dá-se uma provocação para que o sujeito afirme o que está apreendendo. Afirmar algo ou alguém com o juízo que nasce em si ao viver a relação é amor. Assim, afirma-se o real em sua originalidade e afirma-se o acontecimento da própria pessoa ao mesmo tempo. É amor afirmar o outro dizendo "sim" à presença dele para si próprio: ocasião de unidade na própria pessoa. Seria ocasião de ruptura consigo mesmo e com o real se houvesse recusa do acontecimento reconhecido. De fato, amar é aderir a um acontecimento, tornando própria uma novidade que se insinua. Dessa maneira,

não somos nós que criamos o sentido de uma determinada coisa: a ligação que a une a todo o resto é objetiva. A verdadeira experiência é dizer "sim" a uma situação que chama a atenção, ... é tornar nossas as coisas, mas de um modo que se caminhe dentro do seu significado objetivo (Giussani, 1977/2004, p.88)

$\mathrm{Na}$ afirmação do significado objetivo que conecta as vivências e os objetos, a pessoa traz para o presente a própria história. Ela pode estar inteira no instante em que dá sua resposta à provocação advertida no agora, estruturando sua capacidade humana de juízo próprio: "Experiência é o tempo enquanto se identifica com um acontecimento presente, pertencendo ao qual o homem concebe o que é justo e o que não o é, o que deve e o que não deve [fazer ou acontecer]" (Giussani, 2000, p.38).

Afirmando que experiência é caminhar den398 toda a própria história, Giussani adverte que, nesse dinamismo de relação com o real, cada coisa convida a novas conexões, cada acontecimento, a ampliar horizontes. Nesse mesmo sentido, cada momento é ocasião de afirmação de significado e é possível para todos, em qualquer circunstância. 0 real mesmo desperta na pessoa esse dinamismo. Cada ponto pode ser tomado em suas conexões com um horizonte de totalidade e a pessoa pode carregar para sempre uma descoberta importante sobre si e sobre o mundo, facilitando a afirmação de novas evidências e acontecimentos, buscando significado a cada vivência, a cada momento.

Mesmo uma experiência de grande dor pode se tornar um ponto de referência importantíssimo para o indivíduo ao longo de toda a vida, tornandose provocação para outros. Dá-se uma expansão: a apreensão de significados objetivos vai abrindo novos desafios e novos significados em horizontes sempre mais amplos, até o significado último, podendo a pessoa elaborar o sentido que a vida mesma tem. Não apenas o significado de um gesto, de um momento, de um acontecimento, mas o significado da vida pessoal e o da vida mesma. Caminhar dentro do significado objetivo pode formar muitos círculos concêntricos.

Nessa dinâmica de ampliação de horizontes, o próprio sujeito da experiência é quem cresce: aderir e amar incrementa a capacidade de aderir e amar em um círculo virtuoso (Giussani, 1977/2004). O fortalecimento é do sujeito, de modo que a adesão a um significado objetivo em um campo de vida pode ativar o mesmo tipo de processo em outro campo, como que a derramar novas luzes para nova sensibilidade na relação com o real e, portanto, novas apreensões de significado.

"A verdadeira experiência mergulha no ritmo do real e faz tender irresistivelmente para uma unificação até o aspecto último das coisas" (Giussani, 1977/2004, p.88). Ao "mergulhar no ritmo do real" dá-se a sintonia. Deixar acontecer e envolver-se com o acontecimento são expressões da afirmação do real a que Giussani chama de amor, o qual gera unificação da pessoa, entre pessoas, entre pessoa e mundo, entre a pessoa e o mistério do ser.

A cultura contemporânea tende a polemizar a consistência do real e de seus significados obje- 
tivos. No entanto, Giussani aponta a razoabilidade da busca empreendida pela pessoa no campo de penumbra do real da seguinte maneira:

Montale diz: "Olho para trás e não há nada". ... . Montale errou, por quê? Porque, dizendo que as coisas não existem, sobrecarrega de significado um aspecto eliminando outro. É verdade que as coisas são contingentes - isto é, há um momento em que não existem mais -, porém existem. Então, não é adequado: "tudo é" ou "tudo é nada" (o que dá na mesma); a única coisa que existe é o ser e tudo o que existe é nada. Não se pode afirmar isso esquecendo que as coisas existem (Giussani, 2000, p.235).

Afirmar o real é afirmar uma provocação presente, provocação de uma presença mobilizadora, presença de alguém, presença do mundo ou presença da vida da pessoa à pessoa mesma. Uma presença abre perspectivas a serem examinadas. "A realidade, enquanto conhecida, é uma promessa que desperta o apego que o homem tem a essa promessa" (Giussani, 2000, p.274). O fato de que você esteja vivo desperta uma promessa; a questão é que apego você tem a essa promessa (não apenas à vida em seus elementos empíricos) (López, 2010).

A promessa aponta o significado da realidade através da vida na pessoa. No passar das coisas diante de si se desperta uma promessa: "É pau, é pedra, é o fim do caminho... é promessa de vida no meu coração", como, agudamente, Tom Jobim registrou na bela canção "Águas de Março" (Cabral, 1997, p.298). A consistência da experiência tem a ver com a própria adesão à promessa de vida advertida, a despeito das previsões, das emoções ou ideologias. E a realidade que passa é conhecida na medida em que a pessoa se apega, adere, afirma e ama aquela promessa que ali brota. Do contrário, há cisão da experiência, falta de unidade em si mesma e no mundo, inconsistência do real.

O lugar da experiência é o acontecimento, não uma ideia; é o real com as relações objetivas, com sua estrutura não posta pela pessoa mesma. É dentro do real com sua estrutura de significado própria que a pessoa pode colher promessas.

Giussani lembra que essa possibilidade de experiência envolve afirmação, adesão, amor e também uma luta contra forças de divisão presentes na pessoa, em relacionamentos e na cultura, posicionando-se contra o que "não considerar a ligação objetiva" (Giussani, 1977/2004, p.89). Sem essa contraposição, a afirmação se tornaria reduzida aos vínculos imediatos, gerando dificuldades quanto às grandes aspirações. Pode-se dizer que é o drama retratado no romance "A insustentável leveza do ser" (Kundera, 1985): a defesa da liberdade reduzida a sair de certos esquemas acaba por tornar insuportável permanecer diante de alguém livre e realizado. Se a liberdade for radicalmente defendida em sua provocação e promessa advertida, será a defesa da experiência de todos.

A letra da canção "Luz do sol", de Caetano Veloso (1983), pode ajudar a tematizar a gravidade de reduções da experiência e a importância da unidade pessoa-mundo vivida na experiência. "Luz do sol que a folha traga e traduz em verde novo, em folha, em graça, em vida, em força, em luz". Com a folha é com a vida mesma que se lida e nessa consciência ampla, nessa "situação original", emerge a consciência viva de que se pode lidar mal com o real e seu significado objetivo. "Marcha o homem sobre o chão, leva no coração uma ferida acesa: dono do sim e do não diante da visão da infinita beleza, finda por ferir com a mão essa delicadeza, a coisa mais querida: a glória da vida".

Na experiência em que consciência de si pode estar em unidade com a consciência do mundo,

o homem afirma verdadeiramente a si mesmo aceitando a realidade, pois a sua própria realidade é parte da realidade que, como a própria, antes não existia e momento por momento acontece. Por isso, toda natureza do homem está voltada a identificar-se com ela, isto é, a exprimir a unidade original, nativa, a meta última de realização que qualifica todo movimento, o movimento da natureza. Também o homem, como todo o movimento da natureza, escancara o olhar para o presente, abre-se para o presente; reconhece, isto é, aceita, assimila-se ao presente, ama o presente, selecionando o mais e o menos (Giussani, 2000, p.38). 


\section{A originalidade da noção giussaniana de experiência}

Para Giussani,

experiência é o emergir da realidade à consciência do ser humano, é o tornar-se transparente da realidade ao olhar humano. Assim, a realidade é algo em que nos embatemos, é um dado, e a razão é aquele nível da criação em que ela se torna consciência de si mesma (Giussani, 2002, p.107).

Ou ainda, a experiência pode ser tomada como o emergir da realidade à consciência, com a evidência da sua estrutura - explicativa e dinâmica, definitiva e definidora. A sua estrutura definitiva, ou a descrição definidora de sua estrutura, é que o emergir da realidade na experiência contém os princípios avaliadores - por não ser simplesmente provar, mas um provar julgado -, contém em si os princípios que julgam, isto é, princípios de bem e de mal, do ser e do não ser (Giussani, 1999, p.316).

Giussani chega à sua noção de experiência como síntese original a partir da Neoescolástica (com E. Przywara e J. Pieper), do Personalismo (com E. Mounier, R. Guardini e C. S. Lewis) e do Existencialismo (com M. Blondel), em que autenticidade não cai em relativismo, bem como subjetividade e objetividade estão conjugadas (Giussani, 1985; Konrad, 2010). Em Giussani,

um mesmo dinamismo sustenta o surgimento e o desenvolvimento da experiência e do pensamento, confirmando assim que a experiência, quando é autêntica, contém o próprio logos (não o recebe de fora), e que o pensamento, quando é integral, faz aparecer a realidade enquanto tal (Scola, 2006, p.48).

Naquele momento cultural enfrentou-se o problema tipicamente moderno e kantiano de que seria o dado a entrar nas medidas pré-estabelecidas pelo sujeito como condição de possibilidade do conhecimento: sujeito "como autor e legislador da experiência" (Di Martino, 2010, p.25) e não o sujeito cognoscente a comparar-se com o que se dá. Para
(Husserl, 1948/1995), é o dado que se faz presente na experiência.

Essa concepção de experiência assume a doação (o dar-se do fenômeno) como condição de possibilidade, sem pré-determinar suas possibilidades nem seu sentido: é a doação - o acontecer mesmo da realidade, seu mostrar-se -, a estabelecer os contornos da fenomenalidade, a regular e plasmar aquele campo de manifestação que chamamos de experiência (Di Martino, 2010, p.26).

A noção giussaniana de experiência tem condições de evitar, assim, três reduções típicas da contemporaneidade: redução da experiência (a) a fenômeno subjetivo, já que o conteúdo e gênese são acontecimentos; (b) a sentimento, sendo que experiência consiste em colher significado objetivo; e (c) a fenômeno efêmero, uma vez que é aderindo ao significado do real advertido que a pessoa se realiza e cresce (Konrad, 2010). E o faz valorizando extremamente o sujeito (Di Martino, 2010):

o que acontece em toda a realidade se torna autoconsciência no coração do homem: o coração do homem é o lugar em que o céu, a terra, as montanhas... se tornam autoconsciência. O eu consciente de si mesmo é a autoconsciência da natureza inteira. ... . Qualquer momento da autoconsciência se abre, se escancara, está voltada à autoconsciência do todo; como a poesia, que é "intuição lírica num plano cósmico" - no dizer de Benedetto Croce -, expressão lírica, uma expressão de uma pessoa, mas que implica tudo (Giussani, 2000, p.38).

A autoconsciência do pássaro que fende os ares coincide com a autoconsciência do homem que o mira. A autoconsciência do pássaro voando é o homem que o mira (Giussani, 2000, p.38).

\section{Referências}

Ales Bello, A. (2006). Introdução à fenomenologia. Bauru: Edusc.

Ales Bello, A. (2015). Pessoa e comunidade: comentários: Psicologia e Ciências do Espírito de Edith Stein. Belo Horizonte: Artesã. 
Bersanelli, M. (2013). Es posible conocer: Educación en la razón y en la libertad. Madrid: Encuentro.

Bersanelli, M., \& Gargantini, M. (2003). Solo lo stupore conosce: L'avventura della ricerca scientifica. Milano: Rizzoli.

Bondía, J. L. (2002). Notas sobre a experiência e o saber de experiência. Revista Brasileira de Educação, 19, 20-28. Recuperado em dezembro 12, 2015, de http:// www.scielo.br/pdf/rbedu/n19/n19a02.pdf

Borghesi, M. (2015). Luigi Giussani: Conoscenza amorosa ed esperienza del vero: Um itinerário moderno. Bari: Pagina.

Buzzi, E. (Org.) (2003). A generative thought: An introduction to the works of Luigi Giussani. Montreal: McGill Queen's University Press.

Cabral, S. (1997). Antonio Carlos Jobim: uma biografia. Rio de Janeiro: Lumiar.

Chiosso, G. (2004). Teorie dell'educazione e della formazione. Milano: Mondadori Università.

Chiosso, G. (Org.) (2009). Sperare nell'uomo: Giussani, Morin, Maclntyre e la questione educativa. Torino: SEI.

Di Martino, C. (2010). El conocimiento siempre es un acontecimiento. Madrid: Encuentro.

Gaspar, Y. E., \& Mahfoud, M. (2006). Uma leitura histórica do conceito de experiência e uma proposta de compreensão do ser humano em seu caráter essencial: experiência elementar e suas implicações para a Psicologia. Anais do $3^{\circ}$ Seminário Internacional de Pesquisa e Estudos Qualitativos, São Bernardo do Campo, São Paulo, 3, 2006. Recuperado em dezembro 8, 2015, de www.sepq.org.br/IIlsipeq/anais/pdfs/ pchf11.pdf

Giannini, G. (1987). La nozione di esperienza: Implicazioni filosofiche ed esistenziali. Roma: Città Nuova.

Giussani, L. (1985). Seminario con Monsignor Luigi Giussani (6 gennaio 1984). Annuario Teologico 1984, 131-135. Milano: Edit. Recuperado en diciembre 8, 2015, de www.scritti.luigigiussani.org

Giussani, L. (1988). Intervista a Monsignor Luigi Giussani. A cura di P. Antonio Sicari. Communio (Edição Italiana), 98-99, 182-217.

Giussani, L. (1996). Em busca do rosto do homem. São Paulo: Companhia llimitada.

Giussani, L. (1999). L'attrattiva Gesù. Milano: Rizzoli. (Collana Quasi Tischreden, 3).

Giussani, L. (2000). L'autocoscienza del cosmo. Milano: Rizzoli. (Collana Quasi Tischreden, 4).

Giussani, L. (2002). L'uomo e il suo destino: In cammino. Genova: Marietti.

Giussani, L. (2004). Educar é um risco: como criação de personalidade e de história. Bauru: Edusc. (Originalmente publicado em 1977).

Giussani, L. (2009). O senso religioso. Brasília: Universa. (Originalmente publicado em 1986).
Greuel, M. V. (1998). Experiência, pensar e intuição: introdução à Fenomenologia estrutural. São Paulo: Cone Sul.

Husserl, E. (1995). Esperienza e giudizio: Ricerche sulla genealogia della logica. Milano: Bompiani. (Originariamente pubblicato in 1948).

Konrad, M. (2010). Tendere all'ideale: La morale in Luigi Giussani. Genova: Marietti.

Kundera, M. (1985). A insustentável leveza do ser (63a ed.). Rio de Janeiro: Nova Fronteira.

López, A. (2010). Growing human: The experience of God and of man in the work of Luigi Giussani. Communio (US Edition), 37, 209-242. Retrieved december 8, 2015, from http://www.communioicr.com/files/lopez37-2.pdf

Loureiro, I. (2015). Em busca de uma noção de experiência. Ciência e Cultura, 67(1), 28-32. Recuperado em dezembro 12, 2015, de http://cienciaecultura. bvs.br/pdf/cic/v67n1/v67n1a11.pdf

Mahfoud, M. (2011). La dimensione della responsabilità nella motivazione dell'operatore e nella libertà del soggetto. Atti del $3^{\circ}$ Convegno Operatori Psicosociali, 2010, Verona, Itália (pp.73-85). Milano: Medicina \& Persona.

Mahfoud, M. (2012). Experiência elementar em Psicologia: aprendendo a reconhecer. Brasília: Universa.

Mahfoud, M., \& Massimi, M. (2008). A pessoa como sujeito da experiência: contribuições da Fenomenologia. Memorandum, 14, 52-61. Recuperado em dezembro 12, 2015, de www.fafich.ufmg.br/ memorandum/ a14/mahfoudmassimi02.pdf

Martins, J. G. (2007). Experiência e subjetividade em Claude Romano. In M. J. Cantista (Org.), Desenvo/vimentos da Fenomenologia na contemporaneidade (pp.167-213). Porto: Campo das Letras.

Massimi, M., \& Mahfoud, M. (2007). A pessoa como sujeito da experiência: um percurso na história dos saberes psicológicos. Memorandum, 13, 16-31. Recuperado em dezembro 12, 2015 de www. fafich.ufmg.br/ memorandum/a13/massimimah foud01.htm

Romano, C. (2008). Lo posible y el acontecimiento. Santiago del Chile: Universidad Alberto Hurtado.

Scola, A. (2006). Luigi Giussani: Un pensamiento original. Madrid: Encuentro.

Severino, E. (2007). La struttura originaria (Nuova edizione ampliata; $3^{a}$ ed.). Milano: Adelphi.

Simoncini, A., Violini, L., Carozza, P., \& Cartabia, M. (2011). Esperienza elementare e diritto. Milano: Guerini. (Collana Punto di Fuga, 11).

Veloso, C. (1983). Luz do Sol [Compacto simples]. Rio de Janeiro: PolyGram.

Recebido: fevereiro 17, 2016

Aprovado: março 17, 2016 
